\title{
THE ENTIRE FACE IRREGULARITY STRENGTH OF A BOOK WITH POLYGONAL PAGES
}

\author{
Meilin I. Tilukay', Venn Y. I. Ilwaru' \\ 1,2 Jurusan Matematika FMIPA Universitas Pattimura \\ J1. Ir. M. Putuhena, Kampus Unpatti, Poka-Ambon, Indonesia \\ e-mail: ${ }^{1}$ meilin.tilukay@fmipa.unpatti.ac.id
}

\begin{abstract}
A face irregular entire labeling is introduced by Baca et al. recently, as a modification of the well-known vertex irregular and edge irregular total labeling of graphs and the idea of the entire colouring of plane graph. A face irregular entire $k$-labeling $\lambda: V \cup E \cup F \rightarrow\{1,2, \cdots, k\}$ of a 2-connected plane graph $G=(V, E, F)$ is a labeling of vertices, edges, and faces of $G$ such that for any two different faces $f$ and $g$, their weights $w_{\lambda}(f)$ and $w_{\lambda}(f)$ are distinct. The minimum $k$ for which a plane graph $G$ has a face irregular entire $k$-labeling is called the entire face irregularity strength of $G$, denoted by efs $(G)$.
\end{abstract}

This paper deals with the entire face irregularity strength of a book with $m n$-polygonal pages, where embedded in a plane as a closed book with $n$-sided external face.

Keywords and phrases: Book, entire face irregularity strength, face irregular entire $\boldsymbol{k}$-labeling, plane graph, polygonal page.

\section{NILAI KETAKTERATURAN SELURUH MUKA GRAF BUKU SEGI BANYAK}

\begin{abstract}
Abstrak
Pelabelan tak teratur seluruh muka diperkenalkan oleh Baca et al. baru-baru ini, sebagai suatu modifikasi atas pelabelan total tak teratur titik dan tak teratur sisi suatu graf serta ide tentang pewarnaan lengkap pada graf bidang. Pelabelan $k$ - tak teratur seluruh muka $\lambda: V \cup E \cup F \rightarrow\{1,2, \cdots, k\}$ dari suatu graf bidang 2-connected $G=(V, E, F)$ adalah suatu pelabelan seluruh titik, sisi, dan muka internal dari $G$ sedemikian sehingga untuk sebarang dua muka $f$ and $g$ berbeda, bobot muka $w_{\lambda}(f)$ and $w_{\lambda}(f)$ juga berbeda. Bilangan bulat terkecil $k$ sedemikian sehingga suatu graf bidang $G$ memiliki suatu pelabelan $k$-tak teratur seluruh muka disebut nilai ketakteraturan seluruh muka dari $G$, dinotasikan oleh ef $s(G)$.

Kami menentukan nilai eksak dari nilai ketakteraturan seluruh muka graf buku segi- $n$, dimana pada bidang datar dapat digambarkan seperti suatu buku tertutup.
\end{abstract}

Kata Kunci: Graf bidang, graf buku segi-n, nilai ketakteraturan seluruh muka, pelabelan lengkap $\boldsymbol{k}$-tak teratur muka.

\section{Introduction}

Let $G$ be a finite, simple, undirected graph with vertex set $V(G)$ and edge set $E(G)$. A total labeling of $G$ is a mapping that sends $V \cup E$ to a set of numbers (usually positive or nonnegative integers). According to the condition defined in a total labeling, there are many types of total labeling have been investigated.

Baca, Jendrol, Miller, and Ryan in [1] introduced a vertex irregular and edge irregular total labeling of graphs. For any total labeling $f: V \cup E \rightarrow\{1,2, \ldots, k\}$, the weight of a vertex $v$ and the weight of an edge $e=x y$ are defined by $w(v)=f(v)+\sum_{u v \in E} f(u v)$ and $w(x y)=f(x)+f(y)+f(x y)$, respectively. If all the vertex weights are distinct, then $f$ is called a vertex irregular total $k$-labeling, and if all the edge weights are distinct, then $f$ is called an edge irregular total $k$-labeling. The minimum value of $k$ for which there exist a vertex (an edge) irregular total labeling $f: V \cup E \rightarrow\{1,2, \ldots, k\}$ is called the total vertex (edge) irregularity 
strength of $G$ and is denoted by $\operatorname{tvs}(G)$ (tes $(G)$ ), respectively. There are several bounds and exact values of tvs and tes were determined for different types of graphs given in [1] and listed in [2].

Furthermore, Ivanco and Jendrol in [3] posed a conjecture that for arbitrary graph $G$ different from $K_{5}$ and maximum degree $\Delta(G)$,

$$
\operatorname{tes}(G)=\max \left\{\left\lceil\frac{|E(G)|+2}{3}\right\rceil,\left\lceil\frac{\Delta(G)+1}{2}\right]\right\} .
$$

Combining previous conditions on irregular total labeling, Marzuki et al. [4] defined a totally irregular total labeling. A total $k$-labeling $f: V \cup E \rightarrow\{1,2, \ldots, k\}$ of $G$ is called a totally irregular total $k$-labeling if for any pair of vertices $x$ and $y$, their weights $w(x)$ and $w(y)$ are distinct and for any pair of edges $x_{1} x_{2}$ and $y_{1} y_{2}$, their weights $w\left(x_{1} x_{2}\right)$ and $w\left(y_{1} y_{2}\right)$ are distinct. The minimum $k$ for which a graph $G$ has totally irregular total labeling, is called total irregularity strength of $G$, denoted by $t s(G)$. They have proved that for every graph $G$,

$$
\operatorname{ts}(G) \geq \max \{\operatorname{tes}(G), \operatorname{tvs}(G)\}
$$

Several upper bounds and exact values of $t s$ were determined for different types of graphs given in [4], [5], [6], and [7].

Motivated by this graphs invariants, Baca et al. in [8] studied irregular labeling of a plane graph by labeling vertices, edges, and faces then considering the weights of faces. They defined a face irregular entire labeling.

A 2-connected plane graph $G=(V, E, F)$ is a particular drawing of planar graph on the Euclidean plane where every face is bound by a cycle. . Let $G=(V, E, F)$ be a plane graph.

A labeling $\lambda: V \cup E \cup F \rightarrow\{1,2, \cdots, k\}$ is called a face irregular entire $k$-labeling of the plane graph $G$ if for any two distinct faces $f$ and $g$ of $G$, their weights $w_{\lambda}(f)$ and $w_{\lambda}(f)$ are distinct. The minimum $k$ for which a plane graph $G$ has a face irregular entire $k$-labeling is called the entire face irregularity strength of $G$, denoted by efs $(G)$. The weight of a face $f$ under the labeling $\lambda$ is the sum of labels carried by that face and the edges and vertices of its boundary. They also provided the boundaries of efs $(G)$.

Teorema A. Let $G=(V, E, F)$ be a 2 -connected plane graph $G$ with $n_{i} i$-sided faces, $i \geq 3$. Let $a=\min \left\{i \mid n_{i} \neq 0\right\}$ and $b=\max \left\{i \mid n_{i} \neq 0\right\}$. Then

$$
\left\lceil\frac{2 a+n_{3}+n_{4}+\cdots+n_{b}}{2 b+1}\right\rceil \leq \operatorname{efs}(G) \leq \max \left\{n_{i} \mid 3 \leq i \leq b\right\}
$$

For $n_{b}=1$, they gave the lower bound as follow

Teorema B. Let $G=(V, E, F)$ be a 2 -connected plane graph $G$ with $n_{i} i$-sided faces, $i \geq 3$. Let $a=\min \left\{i \mid n_{i} \neq 0\right\}, b=\max \left\{i \mid n_{i} \neq 0\right\}, n_{b}=1$ and $c=\max \left\{i \mid n_{i} \neq 0, i<b\right\}$. Then

$$
\text { ef } s(G) \geq\left\lceil\frac{2 a+|F|-1}{2 c+1}\right\rceil \text {. }
$$

Moreover, by considering the maximum degree of a 2-connected plane graph $G$, they obtained the following theorem.

Theorem C. Let $G=(V, E, F)$ be a 2-connected plane graph $G$ with maximum degree $\Delta$. Let $x$ be a vertex of degree $\Delta$ and let the smallest (and biggest) face incident with $x$ be an $a$-sided (and a $b$-sided) face, respectively. Then

$$
\text { efs }(G) \geq\left\lceil\frac{2 a+\Delta-1}{2 b}\right\rceil
$$

They proved that Theorem B is tight for Ladder graph $L_{n}, n \geq 3$, and its variation and Theorem $\mathrm{C}$ is tight for wheel graph $W_{n}, n \geq 3$. In this paper, we determine the exact value of efs of a book with $m$ $n$-polygonal pages which is greater than the lower bound given in Theorem A - C. 


\section{Main Results}

Considering Theorem C, efs $\left(W_{n}\right)$, and a condition where every face of a plane graph shares common vertices or edges, our first result provide a lower bound of the entire face irregularity strength of a graph with this condition. This can be considered as generalization of Theorem A, B, and C.

Lemma 2.1. Let $G=(V, E, F)$ be a 2-connected plane graph with $n_{i} i$-sided faces, $i \geq 3$. Let $a=\min \left\{i \mid n_{i} \neq 0\right\}, b=\max \left\{i \mid n_{i} \neq 0\right\}, c=\max \left\{i \mid n_{i} \neq 0, i<b\right\}$, and $d$ be the number of common labels of vertices and edges which have bounded every face of $G$. Then

$$
\text { efs }(G) \geq \begin{cases}\left\lceil\frac{2 a+|F|-d-1}{2 c-d+1}\right\rceil, & \text { for } n_{b}=1, \\ \left\lceil\frac{2 a+|F|-d}{2 b-d+1}\right], & \text { otherwise. }\end{cases}
$$

Proof. Let $\lambda: V \cup E \cup F \rightarrow\{1,2, \cdots, k\}$ be a face irregular entire $k$-labeling of 2-connected plane graph $G=(V, E, F)$ with ef $s(G)=k$. Our first proof is for $n_{b} \neq 1$. By Theorem A, the minimum face-weight is at least $2 a+1$ and the maximum face-weight is at least $2 a+|F|$. Since $G$ is 2 -connected, each face of $G$ is a cycle. It implies that every face might be bounded by common vertices and edges.

Let $d$ be the number of common labels of vertices and edges which have bounded every face of $G$ and $D$ be the sum of all common labels. Then the face-weights $w_{\lambda}\left(f_{1}\right), w_{\lambda}\left(f_{1}\right), \cdots, w_{\lambda}\left(f_{|F|}\right)$ are all distinct and each of them contains $D$, implies the variation of face-weights is depend on $2 a-d+2 \leq i \leq 2 b-d+1$ labels. Without adding $D$, the maximum sum of a face label and all vertices and edges-labels surrounding it is at least $2 a+|F|-d$. This is the sum of at most $2 b-d+1$ labels. Thus, we have efs $(\mathrm{G}) \geq\left\lceil\frac{2 a+|F|-d}{2 b-d+1}\right\rceil$.

For $n_{b}=1$, it is a direct consequence from Theorem $\mathrm{B}$ with the same reason as in the result above.

This lower bound is tight for ladder graphs and its variation and wheels given in [8].

A book with $m n$-polygonal pages $B_{m}^{n}, m \geq 1, n \geq 3$, is a plane graph obtained from $m$-copies of cycle $C_{n}$ that share a common edge. There are many ways drawing $B_{m}^{n}$ for which the external face of $B_{m}^{n}$ can be an $n$-sided face or a $(2 n-2)$-sided face.

By considering that topologically, $B_{m}^{n}$ can be drawn on a plane as a closed book such that $B_{m}^{n}$ has an $n$-sided external face, an $n$-sided internal face, and $m-1$ number of $(2 n-2)$-sided internal faces, the entire face irregularity strength of $B_{m}^{n}$ is provided in the next theorem.

Theorem 2.2. For $B_{m}^{n}, m \geq 1, n \geq 3$, be a book with $m n$-polygonal pages whose an $n$-sided external face, an $n$-sided internal face, and $m-1(2 n-2)$-sided internal faces, we have

$$
\text { ef } s\left(B_{m}^{n}\right)= \begin{cases}2, & \text { for } m \in\{1,2\} \\ \left\lceil\frac{4 n+m-7}{4 n-5}\right\rceil, & \text { otherwise }\end{cases}
$$

Proof. Let $B_{m}^{n}, m \geq 1, n \geq 3$, be a 2-connected plane graph. For $m \in\{1,2\}$, by Lemma 2.1 , we have ef $s\left(B_{m}^{n}\right) \geq 2$. Labeling the $n$-sided external face by label 2 and all the rests by label 1 , then all face-weights are distinct. Thus, efs $\left(B_{m}^{n}\right)=2$.

Now for $m>2$, let $z=\operatorname{efs}\left(B_{m}^{n}\right)$. Since every internal face of $B_{m}^{n}$ shares 2 common vertices, $a=n$, $b=2 n-2$, and $n_{b}>1$, by Lemma 2.1 , we have $z \geq\left\lceil\frac{2 a+|F|-2}{2 b-1}\right\rceil=\left\lceil\frac{2 n+m-1}{4 n-5}\right\rceil$. Consider that $z=\left\lceil\frac{2 n+m-1}{4 n-5}\right\rceil$ is not valid, since for $m \leq 2 n-4$, the maximum label is 1 .

Moreover, since $B_{m}^{n}$ has at least 2 face-weights which are contributed by the same number of labels, there must be 2 faces of the same weight. Then the divisor must be at least $4 n-4$. Thus we have $z \geq\left\lceil\frac{4 n+m-7}{4 n-5}\right\rceil$. 
Next, to show that $z$ is an upper bound for entire face irregularity strength of $B_{m}^{n}$, let $B_{m}^{n}, m \geq 1, n \geq 3$, be the 2-connected plane graph with an $n$-sided internal face $f_{i n t}^{n}, m-1(2 n-2)$-sided internal faces and an external $n$-sided face $f_{\text {ext }}^{n}$.

Let $m_{1}=\left\lceil\frac{m}{2}\right\rceil$ and $m_{2}=m-m_{1}$. Our goal is to have $m_{1}$ distinct even face-weights and $m_{2}$ distinct odd face-weights such that $m(2 n-2)$-sided face-weights are distinct and form an arithmetic progression.

Let $z=\left\lceil\frac{4 n+m-7}{4 n-5}\right\rceil$. It can be seen that $B_{m}^{n}$ has $m$ different paths of length $(n-1)$. Next, we divide $m_{1}$ paths into $S=\left[\frac{m_{1}}{4 n-5}\right\rceil$ parts, where part $s$-th consists of $(4 n-5)$ paths, for $1 \leq s \leq S-1$, and part $S$-th consists of $r_{1}=m_{1}-(S-1)(4 n-5)$ paths. Also, we divide $m_{2}$ paths into $T=\left\lceil\frac{m_{2}+1}{4 n-5}\right\rceil$ parts, where the first part consists of $(4 n-6)$ paths, part $t$-th consists of $(4 n-5)$ paths, for $2 \leq t \leq T-1$, and part $T$-th consists of $r_{2}=m_{2}-(T-1)(4 n-5)$ paths.

Let

$$
\begin{aligned}
V\left(B_{m}^{n}\right)= & \left\{x, y, u(s)_{i}^{2 j}, u(S)_{k}^{2 j}, v(t)_{i}^{2 j} \neq v(1)_{1}^{2 j}, v(T)_{l}^{2 j} \mid 1 \leq s \leq S-1,1 \leq t \leq T-1,1 \leq i \leq 4 n-\right. \\
& \left.5,1 \leq j \leq 2 n-2,1 \leq k \leq r_{1}, 1 \leq l \leq r_{2}\right\} ; \\
E\left(B_{m}^{n}\right)= & \{x y\} \cup \\
& \left\{u(s)_{i}^{1}=x u(s)_{i}^{2}, u(s)_{i}^{2 j-1}=u(s)_{i}^{2 j-2} u(s)_{i}^{2 j}, u(s)_{i}^{2 n-3}=u(s)_{i}^{2 n-4} y \mid 1 \leq s \leq S-1,1 \leq\right. \\
& i \leq 4 n-5,2 \leq j \leq n-2\} \cup \\
& \left\{u(S)_{i}^{1}=x u(S)_{i}^{2}, u(S)_{i}^{2 j-1}=u(S)_{i}^{2 j-2} u(S)_{i}^{2 j}, u(S)_{i}^{2 n-3}=u(S)_{i}^{2 n-4} y \mid 1 \leq i \leq r_{1}, 2 \leq j \leq\right. \\
& n-2\} \cup \\
& \left\{v(t)_{i}^{1}=x v(t)_{i}^{2}, v(t)_{i}^{2 j-1}=v(t)_{i}^{2 j-2} v(t)_{i}^{2 j}, v(t)_{i}^{2 n-3}=v(t)_{i}^{2 n-4} y \mid 1 \leq t \leq T, 1 \leq i \leq 4 n-\right. \\
& 5,2 \leq j \leq n-2\} \cup \\
& \left\{v(T)_{i}^{1}=x v(T)_{i}^{2}, v(T)_{i}^{2 j-1}=v(T)_{i}^{2 j-2} v(T)_{i}^{2 j}, v(T)_{i}^{2 n-3}=v(T)_{i}^{2 n-4} y \mid 1 \leq i \leq r_{2}, 2 \leq j \leq\right. \\
& n-2\} ; \\
F\left(B_{m}^{n}\right)= & \left\{f_{\text {ext }}^{n}, f_{i n t}^{n}, u(s)_{i}^{2 n-2}, u(S)_{k}^{2 n-2}, v(t)_{i}^{2 n-2} \neq v(1)_{1}^{2 n-2}, v(T)_{j}^{2 n-2} \mid 1 \leq s \leq S-1,1 \leq t \leq T-\right. \\
& \left.1,1 \leq i \leq 4 n-5,1 \leq k \leq r_{1}, 1 \leq l \leq r_{2}\right\} ;
\end{aligned}
$$

Where $f_{\text {ext }}^{n}$ is bounded by cycle $x v(1)_{2}^{2} v(1)_{2}^{4} \cdots v(1)_{2}^{2 n-4} y x$;

$f_{i n t}^{n}$ is bounded by cycle $x u(1)_{1}^{2} u(1)_{1}^{4} \cdots u(1)_{1}^{2 n-4} y x$;

$u(s)_{i}^{2 n-2}$ is bounded by cycle $x u(s)_{i}^{2} u(s)_{i}^{4} \cdots u(s)_{i}^{2 n-4} y u(s)_{i+1}^{2 n-4} u(s)_{i+1}^{2 n-6} \cdots u(s)_{i+1}^{2} x$, for $1 \leq s \leq S, i \neq r_{1}$;

$u(S)_{r_{1}}^{2 n-2}$ is bounded by cycle $x u(S)_{r_{1}}^{2} u(S)_{r_{1}}^{4} \cdots u(S)_{r_{1}}^{2 n-4} y v(T)_{r_{2}}^{2 n-4} v(T)_{r_{2}}^{2 n-6} \cdots v(T)_{r_{2}}^{2} x$; and $v(t)_{i}^{2 n-2}$ is bounded by cycle $x v(t)_{i}^{2} v(t)_{i}^{4} \cdots v(t)_{i}^{2 n-4} y v(t)_{i+1}^{2 n-4} v(t)_{i+1}^{2 n-6} \cdots v(t)_{i+1}^{2} x$, for $1 \leq t \leq T, i \neq r_{2}$

Our notations above imply that, without losing generality, for $v(t)_{i}^{j}$, we let $2 \leq i \leq 4 n-5$ for $t=1$. It means that there is no vertex or edge or face $v(1)_{1}^{j}$.

Now, we divide our labeling of $B_{m}^{n}$ into 2 cases as follows:

\section{Case 1. For odd $\boldsymbol{m}$ with $2 \leq \boldsymbol{r}_{\mathbf{2}} \leq \mathbf{2 n}-\mathbf{1}$ or even $\boldsymbol{m}$;}

Define an entire $k$-labeling $\lambda: V \cup E \cup F \rightarrow\{1,2, \cdots, k\}$ of $B_{m}^{n}$ as follows.

$\lambda(x)=\lambda(y)=\lambda(x y)=\lambda\left(f_{\text {ext }}^{n}\right)=1$;

$\lambda\left(f_{\text {int }}^{n}\right)=2$; 


$$
\begin{aligned}
& \lambda\left(u(s)_{i}^{j}\right)= \begin{cases}2 s-1 & \text { for } 1 \leq s \leq S, 1 \leq i \leq \min \left\{r_{1}, 2 n-2\right\} \text { and } 1 \leq j \leq 2 n-i-1 \\
2 s & \text { for } 1 \leq s \leq S, 1 \leq i \leq \min \left\{r_{1}, 2 n-2\right\} \text { and } 2 n-i \leq j \leq 2 n-2 \\
2 s & \text { for } 1 \leq s \leq S, 2 n-1 \leq i \leq \min \left\{r_{1}, 4 n-5\right\} \text { and } 1 \leq j \leq 2 n-2\left\lfloor\frac{i-2 n+2}{2}\right\rfloor-2 \\
2 s+1 & \text { for } 1 \leq s \leq S, 2 n-1 \leq i \leq \min \left\{r_{1}, 4 n-5\right\} \text { and } 2 n-2\left\lfloor\frac{i-2 n+2}{2}\right\rfloor-1 \leq j \leq 2 n-2\end{cases} \\
& \lambda\left(v(t)_{i}^{j}\right)=\left\{\begin{array}{cl}
2 t-1, & \text { for } 1 \leq t \leq T, 1 \leq i \leq \min \left\{r_{2}, 2 n-2\right\} \text { and } 1 \leq j \leq 2 n-i-2 ; \\
2 t, & \text { for } 1 \leq t \leq T, 1 \leq i \leq \min \left\{r_{2}, 2 n-2\right\} \text { and } 2 n-i-1 \leq j \leq 2 n-3 \\
2 t, & \text { for } 1 \leq t \leq T, 2 n-1 \leq i \leq \min \left\{r_{2}, 4 n-5\right\} \text { and } 1 \leq j \leq 2 n-2\left[\frac{i-2 n+2}{2}\right\rfloor-3 ; \\
2 t+1, & \text { for } 1 \leq t \leq T, 2 n-1 \leq i \leq \min \left\{r_{2}, 4 n-5\right\} \text { and } 2 n-2\left[\frac{i-2 n+2}{2}\right\rfloor-2 \leq j \leq 2 n-3 ; \\
2 t-2, & \text { for } 1 \leq t \leq T, i=1 \text { and } j=2 n-2 ; \\
2 t-1, & \text { for } 1 \leq t \leq T, 2 \leq i \leq \min \left\{r_{2}, 2 n-1\right\} \text { and } j=2 n-2 ; \\
2 t, & \text { for } 1 \leq t \leq T-1,2 n \leq i \leq 4 n-5 \text { and } j=2 n-2 . \\
2 t, & \text { for } t=T, 2 n-1 \leq i \leq \min \left\{r_{2}-1,4 n-6\right\} \text { and } j=2 n-2
\end{array}\right.
\end{aligned}
$$

\section{Case 2. For odd $m$ with $r_{2}=1$ or $2 n \leq r_{2} \leq 4 n-5$;}

Define an entire $k$-labeling $\lambda^{*}: V \cup E \cup F \rightarrow\{1,2, \cdots, k\}$ of $B_{m}^{n}$ as follows.

$$
\begin{aligned}
& \lambda^{*}(x)=\lambda^{*}(y)=\lambda^{*}(x y)=\lambda^{*}\left(f_{\text {ext }}^{n}\right)=1 ; \\
& \lambda^{*}\left(f_{\text {int }}^{n}\right)=2 ; \\
& \lambda^{*}\left(u(s)_{i}^{j}\right)=\lambda\left(u(s)_{i}^{j}\right) \\
& \lambda^{*}\left(v(t)_{i}^{j}\right)= \begin{cases}2 T-2, & \text { for } r_{2}=1, t=T, i=1, j=1 ; \\
2 T-1, & \text { for } r_{2}=1, t=T-1, i=4 n-5, j=2 n-2 ; \\
\lambda\left(v(t)_{i}^{j}\right)+1, & \text { for } r_{2} \text { odd, } 2 n \leq r_{2} \leq 4 n-5, t=T, i=r_{2}, j=1 ; \\
\lambda\left(v(t)_{i}^{j}\right)-1, & \text { for } r_{2} \text { odd, } 2 n \leq r_{2} \leq 4 n-5, t=T, i=r_{2}-1, j=2 n-2 ; \\
\lambda\left(v(t)_{i}^{j}\right)-1, & \text { for } r_{2} \text { even, } 2 n \leq r_{2} \leq 4 n-5, t=T, i=r_{2}-1, j=2 n-3 ; \\
\lambda\left(v(t)_{i}^{j}\right)+1, & \text { for } r_{2} \text { even, } 2 n \leq r_{2} \leq 4 n-5, t=T, i=r_{2}-1, j=2 n-2 ; \\
\lambda\left(v(t)_{i}^{j}\right), & \text { for otherwise. }\end{cases}
\end{aligned}
$$

It is easy to check that the labeling $\lambda$ is an entire $z$-labeling. Then we have evaluate the face -weights set $\left\{w\left(f_{\text {ext }}^{n}\right), w\left(f_{\text {int }}^{n}\right), w\left(u(s)_{i}^{2 n-2}\right), w\left(v(t)_{i}^{2 n-2}\right) \mid 1 \leq s \leq S, 1 \leq t \leq T, 1 \leq i \leq 4 n-5\right\}$ as follows.

$$
\begin{aligned}
& w\left(f_{\text {ext }}^{n}\right)=2 n+1 ; \\
& w\left(f_{\text {int }}^{n}\right)=2 n+2 ; \\
& w\left(u(s)_{i}^{2 n-2}\right)= \begin{cases}(2 s-1)(4 n-5)+2 i, & \text { for } 1 \leq s \leq S-1,1 \leq i \leq 4 n-5 ; \\
(2 s-1)(4 n-5)+2 i, & \text { for } s=S-1,1 \leq i \leq r_{1} ; \\
(2 s-1)(4 n-5)+2 r_{1}, & \text { for even } m, s=S-1, i=r_{1} ; \\
(2 s-1)(4 n-5)+2 r_{1}-1, & \text { for odd } m, s=S-1, i=r_{1} .\end{cases}
\end{aligned}
$$$$
w\left(v(t)_{i}^{2 n-2}\right)= \begin{cases}(2 t-1)(4 n-5)+2 i+1, & \text { for } 1 \leq t \leq T-1,1 \leq i \leq 4 n-5 ; \\ (2 T-1)(4 n-5)+2 i+1, & \text { for } t=T, 1 \leq i \leq r_{2}-1 .\end{cases}
$$

Since all face-weights are distinct, then $\lambda$ is a face irregular entire z-labeling of $B_{m}^{n}$ where $m$ is odd with $2 \leq r_{2} \leq 2 n-1$ or $m$ is even; and $\lambda^{*}$ is a face irregular entire z-labeling of $B_{m}^{n}$ where $m$ is odd with $r_{2}=1$ or $2 n \leq r_{2} \leq 4 n-5$. Thus, $z=\left\lceil\frac{4 n+m-7}{4 n-5}\right\rceil$ is the entire face irregularity strength of $B_{m}^{n}$.

Note that our result in Theorem 2.2 show that the efs $\left(B_{m}^{n}\right)$ is greater than the lower bound in Lemma 2.1. Hence, we propose the following open problem. 


\section{Open Problems}

1. Find a class of graph which satisfy a condition where the lower bound in Lemma 2.1 is sharp;

2. Generalize the lower bound for any condition.

\section{References}

[1] M. Baca, S. Jendrol, M. Miller and J. Ryan, "On Irregular Total Labelings,” Discrete Mathematics, vol. 307, pp. 1378-1388, 2007.

[2] J. A. Galian, “A Dynamic Survey of Graph Labeling,” Electronic Journal of Combinatorics, vol. 18 \#DS6, 2015.

[3] J. Ivanco and S. Jendrol, "The Total Edge Irregularity Strength of Trees," Discuss. Math. Graph Theory, vol. 26, pp. 449-456, 2006.

[4] C. C. Marzuki, A. N. M. Salman and M. Miller, "On The Total Irregularity Strengths of Cycles and Paths," Far East Journal of Mathematical Sciences, vol. 82 (1), pp. 1-21, 2013.

[5] R. Ramdani and A. N. M. Salman, “On The Total Irregularity Strengths of Some Cartesian Products Graphs,” $A K C E$ Int. J. Graphs Comb., vol. 10 No. 2, pp. 199-209, 2013.

[6] R. Ramdani, A. N. M. Salman, H. Assiyatun, A. Semanicova-Fenovcikova and M. Baca, "Total Irregularity Strength of Three Family of Graphs," Math. Comput. Sci, vol. 9, pp. 229-237, 2015.

[7] M. I. Tilukay, A. N. M. Salman and E. R. Persulessy, "On The Total Irregularity Strength of Fan, Wheel, Triangular Book, and Friendship Graphs," Procedia Computer Science, vol. 74, pp. 124-131, 2015.

[8] M. Baca, S. Jendrol, K. Kathiresan and K. Muthugurupackiam, "Entire Labeling of Plane Graphs," Applied Mathematics and Information Sciences, vol. 9, no. 1, pp. 263-207, 2015. 